\title{
ГЛОБАЛЬНАЯ ДЕМОГРАФИЧЕСКАЯ ТЕОРИЯ
}

\author{
АНДРЕЙ ПОДЛАЗОВ
}

Работа посвящуена построению математической теории глобального демографического прочесса, охватывающей как стадию демографического роста, так и стадию демографического перехода.

На протяжении почти всей истории вида Ното sаріепсе его численность росла в режиме с обострением. Однако в последние десятилетия рост начал замедляться и наметилась тенденция к стабилизации населения мира. Количественное описание нашей популяционной динамики, объяснение ее фундаментальных отличий от популяционной динамики других видов и глобальный демографический прогноз являются первоочередными задачами теоретической демографии. Для их решения в работе введено понятие о жизнесберегающих технологиях, развитие которых трактуется как двигатель истории, и сформулирован принцип технологического императива, прямо привязывающий число живущих людей к технологическому уровню.

Жизнесберегающие технологии создаются в ходе повседневной деятельности людей на основе уже имеюшихся технологий. Их совершенствование, с одной стороны, сокращает смертность, изменение коэффициента которой и определяет уровень технологического развития, а с другой увеличивает число востребованных технологиями людей, обеспечивая ускоряюшийся демографический рост. Однако ограниченность снизу коэффициента смертности создает естественный предел и численности населения, обусловливая демографический переход, который с биологической точки зрения является кризисом.

Одновременно с приближением технологического уровня к предельному значению происходит перестройка возрастной структуры населения. Формальный учет этих двух факторов позволяет построчть феноменологическую модель демографического перехода. Для определения ее параметров разработана методика обработки демографических данных, относящихся к стадии роста. Предложенная модель показала много лучшее согласие с реальностью, чем классические модели глобальной демографии.

Ключевым следствием модели демографического перехода оказывается увеличение в его результате технологической ниши человечества - отношения его численности к уровню жизнесберегаюших технологий. На фоне роста доли взрослых в популящии это чревато неустойчивостями развития, 6 результате которых демографическая стабилизация может смениться сокращением мирового населения.

Ключевые слова: теоретическая демография, глобальная демография, гиперболический закон, режимы с обострением, демографический императив, технологический императив, жизнесберегающие технологии, технологическая ниша, демографический переход, предель роста, возрастная пирамида.

\section{ВВЕДЕНИЕ}

Если предметом изучения традиционной демографии являются состав и движение населения, взятые в географическом, этническом, конфессиональном, социальном, профессиональном и иных разрезах, то глобальная демография имеет дело не с территориями или группами, а исследует демографическую динамику всего человечества как целостной системы.

АндРЕЙ ВИкТОРОвИч ПодЛАЗОв (Tiger@Keldysh.ru), ИНСТИТУТ ПРИКЛАДНОЙ МАТЕМАТИКИ ИМ. М.В. КЕЛДЫША РАН, РОССИЯ.

СТАТЬЯ ПОСТУПИЛА В РЕДАКЦИЮ В МАЕ 2017 Г.

РАБОТА ВЫПОЛНЕНА ПРИ ПОДДЕРЖКЕ РФФИ (ПРОЕКТ №15-01-07944-А) И РГНФ (ПРОЕКТ №15-03-00404-А). 
Сложность предмета рассмотрения предполагает максимальное огрубление, связанное с отказом от учета возрастной, пространственной, социальной, культурной и так далее структуры населения. В простейшем случае внимание сосредоточивается на одной единственной количественной характеристике - населении мира $n$, что дает существенное упрощение за счет исключения из анализа миграционных процессов. Цель глобальной демографии состоит в качественном и количественном описании изменения численности человечества, выявлении определяющих ее механизмов и построении соответствующих математических моделей.

Принципиальной особенностью глобального демографического процесса является то, что на протяжении большей части истории он шел с ускорением (с 1960 по 2000 г. народонаселение удвоилось, на что потребовалось всего 40 лет, однако предыдущее удвоение заняло 65 лет, перед ним - 140, до того - 400, а еще раньше - 1000), которое лишь недавно сменилось замедлением. Ускоряющийся характер роста выражается в том, что со временем увеличивается не только численность населения, но также его годовой прирост (производная) и даже темп прироста (логарифмическая производная), графики которых представлены на рисунке 1. Переход от ускорения к замедлению породил представление о демографическом взрыве - концентрации радикальных популяционных изменений на узком временном интервале.

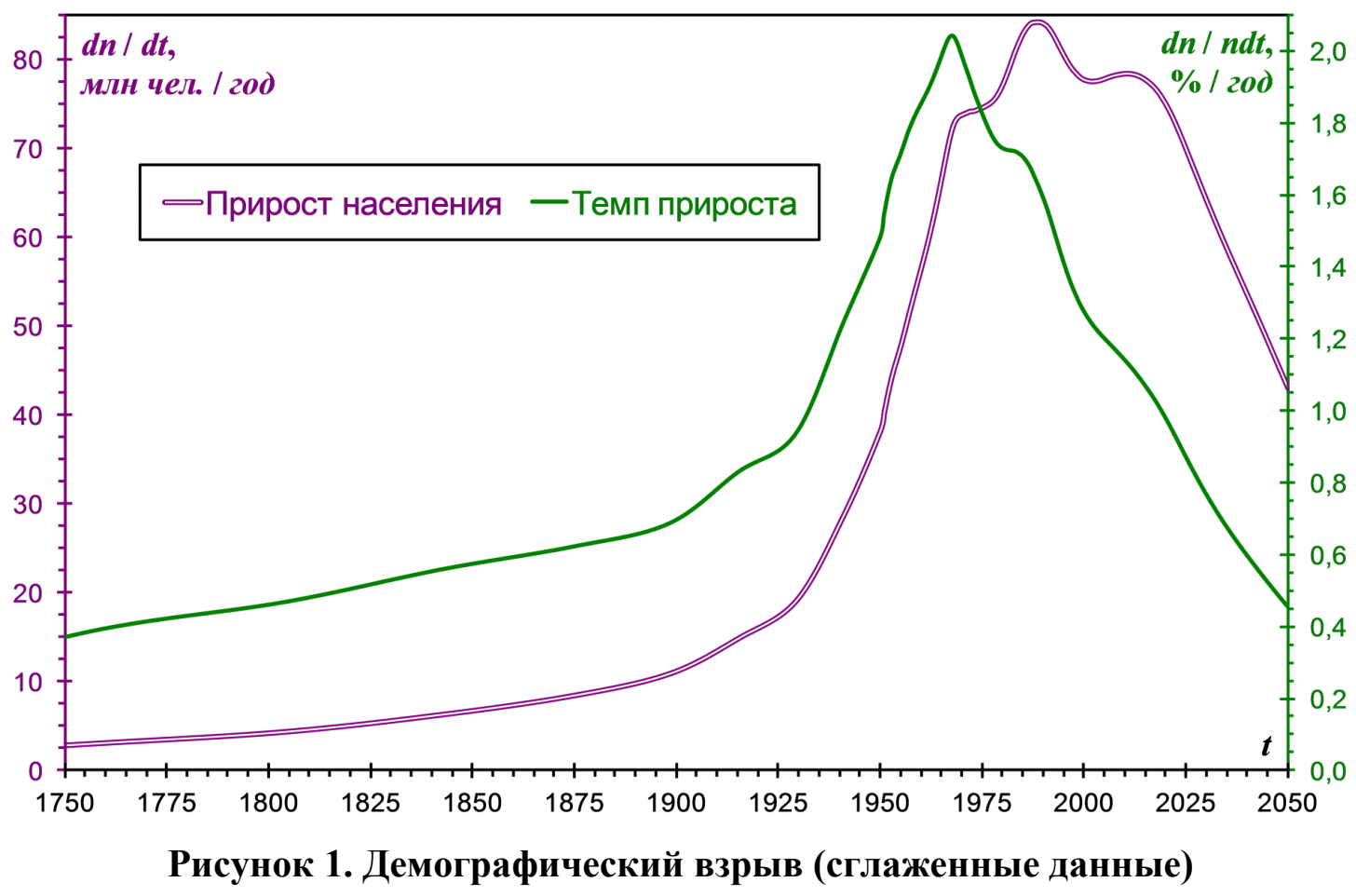

Примечание: Изменение народонаселения подвержено флуктуачиям, которые ранее могли приводить даже кего кратковременному снижению. Однако благодаря ускорению демографического роста кривые уверено поднимаются над нулевой отметкой начиная с XVII века.

Максимальный годовой прирост населения в 88 млн человек имел место в 1989 г., а годовой темп прироста достиг пика в 2,2\% в 1963 г.

Источник: По данным [Kremer 1993; Total midyear population]. 
Рассмотрения рисунке 1 на качественном уровне достаточно, чтобы сформулировать ключевые вопросы, на которые должна ответить глобальная демографическая теория:

1. Почему численность вида Hото sapience вообще растет, тогда как численность любых иных видов, занимающих некоторую экологическую нишу, остается в среднем постоянной?

2. Почему темп прироста народонаселения увеличивался, тогда как даже вид, осваивающий новую экологическую нишу, характеризуется постоянным темпом прироста своей численности?

3. Почему в настоящее время происходит падение скорости роста человечества?

4. Каковы перспективы демографического развития?

Первой попыткой дать ответы на эти вопросы стала феноменологическая модель роста человечества, предложенная С.П. Капицей [Капица и др. 1997; Капица 1999], опирающаяся на сформулированный им принцип демографического императива. Если популяционный принщип, выдвинутый Т. Мальтусом, связывал рост населения с доступными ресурсами, то согласно принципу демографического императива рост населения определяется развитием, т.е. внутренними свойствами системы, а не внешними факторами. Такая точка зрения более чем уместна при рассмотрении демографической динамики всего человечества.

В рамках модели С.П. Капицы развитие связывается с гипотетическим информационным взаимодействием, интенсивность которого пропорциональна числу парных отношений между людьми. К сожалению, механизм, посредством которого информационное взаимодействие между людьми обусловливает рост их количества, остался неясен. Другой трудностью этой гипотезы оказывается невозможность объяснить происходящее ныне замедление роста населения, по мере увеличения численности которого информационное взаимодействие должно только усиливаться. Этой проблемы не решает даже учет эффектов запаздывания, не способных отменить уже возникшее информационное взаимодействие.

В настоящей работе предлагается другой подход, основанный на представлении о жизнесберегающих технологиях и принципе технологического императива, что позволяет непротиворечиво объяснить наблюдаемые явления и построить для них математическую модель.

Начнем с перехода от качественного описания роста к количественному. На рисунке 2 представлена аппроксимация зависимости численности населения от времени формулой:

$$
n(t)=C / \Delta t, \Delta t=t_{f}-t
$$

где $C \approx 200$ млрд чел. $ә$ год , а момент обострения $t_{f}$ приходится на 2025 г. 


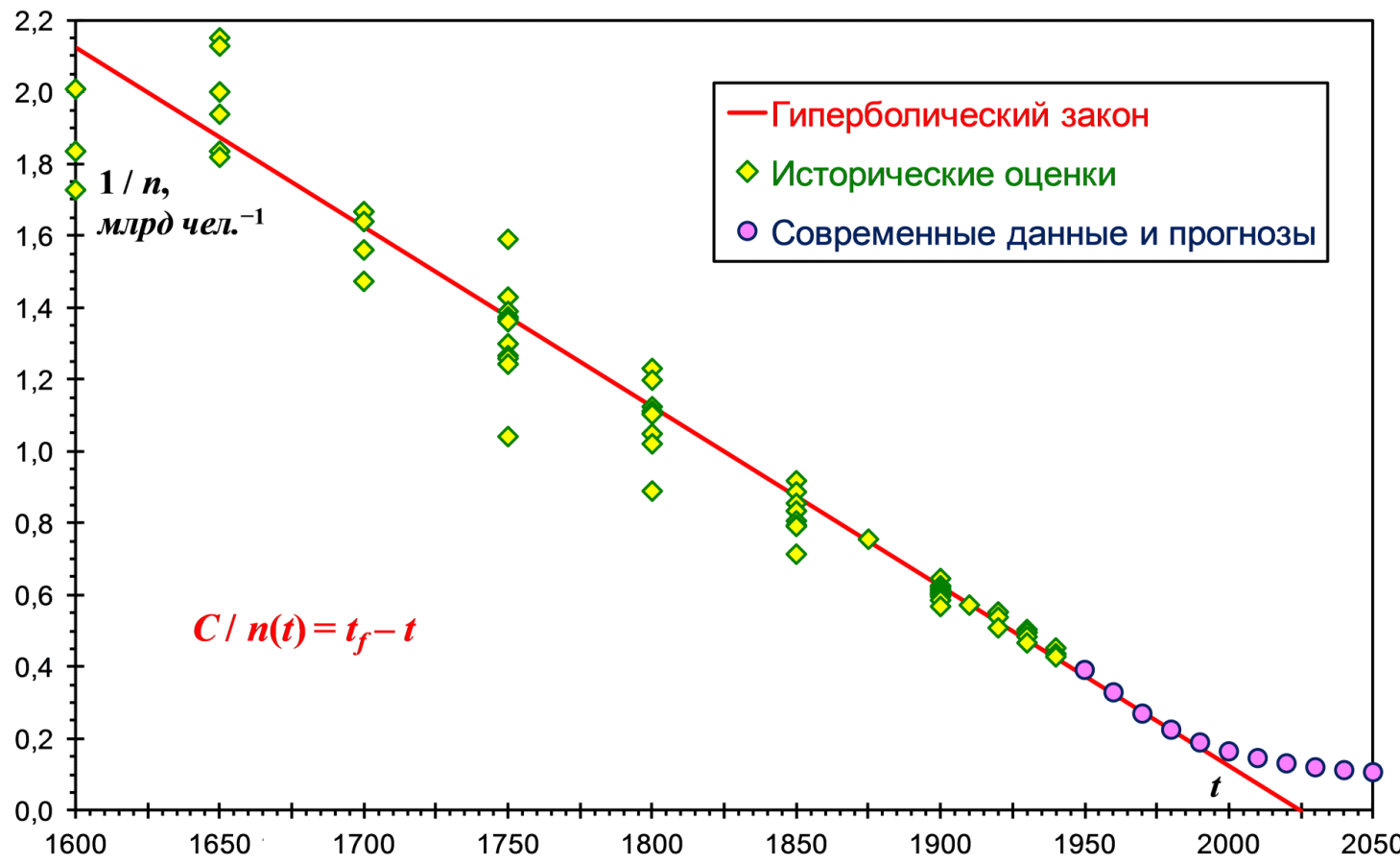

Рисунок 2. Гиперболический рост

Примечание: Данные по населению за 1600-1960 г2. приведены с обратным представлением по оси ординат. Прямая в таких координатах соответствует формуле (1), а пересечение ее продолжения с осью абсиисс определяет момент обострения.

Источники: По данным [Kremer 1993; Total midyear population].

Зависимость вида (1) была впервые обнаружена в 1960 г. [Foerster et al. 1960]. Bскоре после открытия она перестала выполняться, что неудивительно, так как эта формула, становящаяся абсурдной при приближении $t$ к $t_{f}$, очевидно не может быть экстраполирована в будущее. Однако, как можно видеть из рисунка 3 , ее экстраполяция в прошлое по крайней мере до 1,6 млн лет назад находится в удовлетворительном согласии с демографическими данными, дополненными оценками антропологов и палеодемографов.

Иными словами, закон роста (1) выполнялся от нижнего палеолита до возникновения постиндустриального общества. Этот длительный период развития будем называть фазой роста в противоположность происходящему в настоящее время глобальному демографическому переходу, связанному со сменой типа воспроизводства населения. В результате демографического перехода происходит замедление роста населения относительно закона (1) с тенденцией к стабилизации численности.

Именно применимость гиперболического закона на протяжении практически всей истории человека как вида представляется важнейшим обоснованием принципа демографического императива. Общий механизм роста не может быть обусловлен действием сравнительно недавно возникших факторов, связанных с экономикой или культурой. 


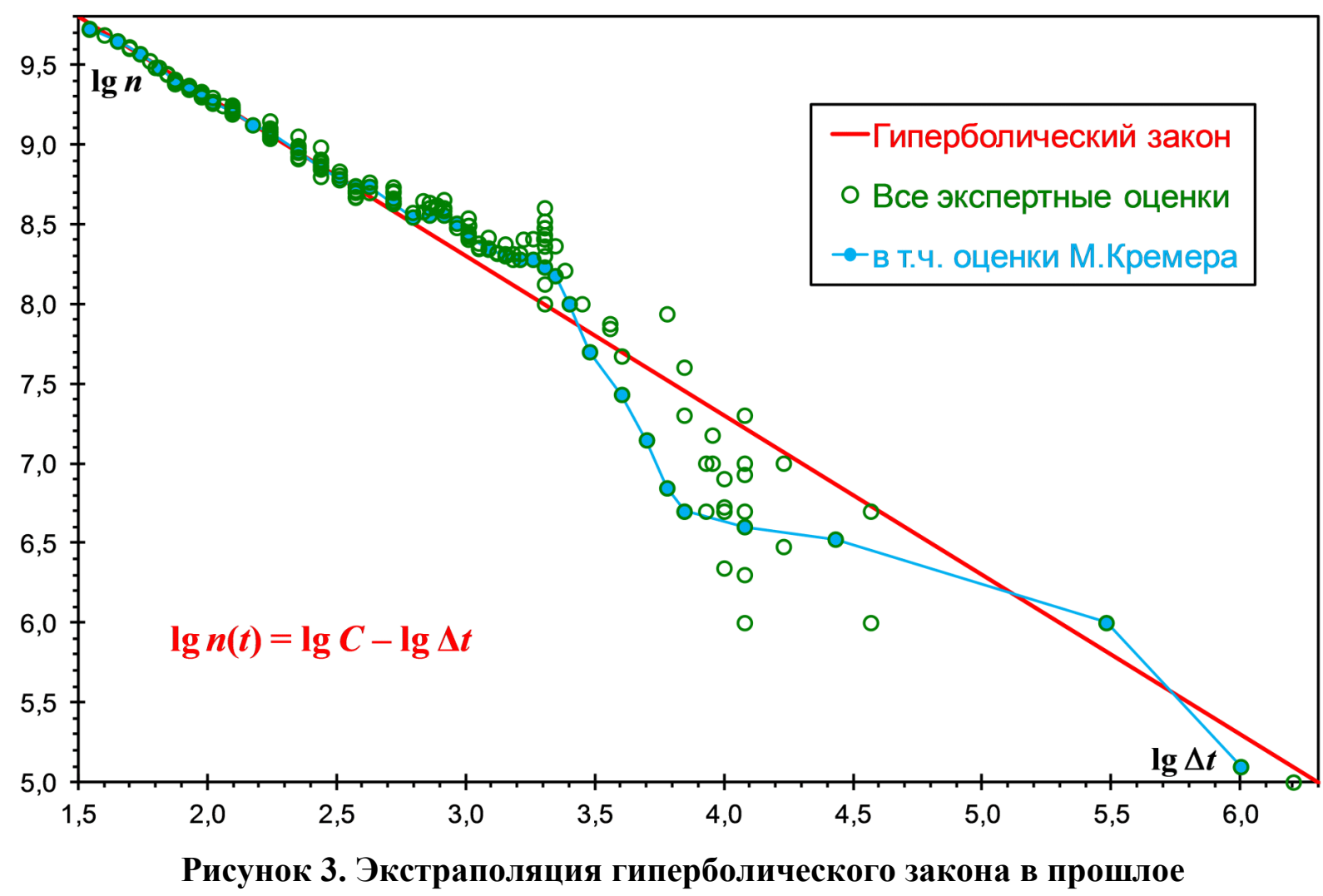

Примечание: Прямая соответствует формуле (1). Заметные отклонения точек от нее соответствуют ледниковому периоду (вниз) и римскому и средневековому климатическим оптимумам (вверх).

Отдельно отмечены данные из работы [Kremеr 1993], образующие временной ряд. Значения остальных точек взяты из источников [Капииа и др. 1997; Kanuйа 1999; Cohen 1995; Historical estimates...] и, будучи получены разными методами, не допускают какой-либо обработки.

Закону (1) соответствует автономное дифференциальное уравнение:

$$
\dot{n}=n^{2} / C,
$$

которое само по себе косвенно подтверждает принципиальную возможность экстраполяции в прошлое, позволяя оценить условия и момент начала антропогенеза. Это событие отмечено минимально возможным значением прироста населения, равным одному человеку за одно поколение. Приняв время смены поколений $\tau \approx 20$ лет, получаем исходную численность популяции:

$$
n_{0}=\sqrt{1 / \tau \cdot C} \approx 100 \text { mыс.чел. }
$$

и момент начала роста $t_{0}=C / n_{0} \approx-2$ млн лет, находящиеся в удовлетворительном согласии с антропологическими данными [Капица 1999]. 


\section{МАТЕМАТИЧЕСКАЯ МОДЕЛЬ ДЕМОГРАФИЧЕСКОГО РОСТА}

\section{Компоненты естественного движсения населения}

Поскольку для мира в целом отсутствует внешняя миграция, его население меняется только за счет рождаемости и смертности. Рассмотрим особенности этих компонент по отдельности.

\section{Pождаемость}

На заре антропогенеза процессы рождения и смерти людей в среднем уравновешивали друг друга. Но далее между ними возник зазор, который до недавнего времени только расширялся, обеспечивая ускоряющийся рост популяции. Принципиально, что зазор не мог появиться вследствие увеличения рождаемости, так как ее уровень обыкновенно занижен по сравнению с предельными репродуктивными возможностями человека.

В процессе своего развития человечество выработало множество социокультурных ограничителей рождаемости: религиозную регламентацию сексуальных отношений, установление возраста совершеннолетия, необходимость дать приданное за невестой или уплатить за нее калым, многоженство, эмансипация женщин, сексуальная революция и др. Действие этих ограничителей позволяет избежать колебаний численности, вызванных эффектами запаздывания. Такие колебания наблюдаются в популяциях многих видов животных. Чрезмерное размножение в благоприятной обстановке впоследствии приводит к перенаселенности, обострению внутривидовой конкуренции и резкому подъему смертности. Люди способны демпфировать подобные колебания, не допуская слишком быстрого роста своей численности. И наоборот, если произошло внезапное сокращение народонаселения, вызванное форс-мажорными обстоятельствами (стихийные бедствия, войны, эпидемии), его можно быстро восстановить, временно отбросив ограничения и подняв рождаемость до естественного уровня.

Таким образом, нет оснований полагать, что рождаемость может систематически увеличиваться. Вместе с тем нет и причин, по которым до начала демографического перехода она могла бы уменьшаться. Поэтому мы будем считать ее уровень неизменным в фазе демографического роста и снижающимся во время демографического перехода.

Сформулированная модель изменения рождаемости не вполне реалистична, поскольку кроме ее социокультурных ограничителей, лишь возникавших по мере развития человечества, существовали и биологические ограничители, снимавшиеся по мере развития. Наиболее значимыми из них были длительное грудное вскармливание, характерное для кочевого образа жизни, и высокая смертность молодых женщин, не позволявшая им полностью реализовать репродуктивную программу. Снятие подобных ограничителей происходило в сравнительно узком промежутке времени. Поскольку отдельный учет краткосрочных событий в модели, описывающий длительный процесс, нецелесообразен, мы будем формально интерпретировать действие биологических ограничителей как фактор смертности, а их снятие - как ее уменьшение. Такое усложнение интерпретации биологических ограничителей рождаемости позволяет получить более простое описание ее динамики. 


\section{Смертность}

Исключение рождаемости из числа факторов, обусловливающих рост народонаселения, заставляет предположить, что он связан со снижением смертности. Нелинейный вид правой части уравнения (2) свидетельствует о том, что мы имеем дело с коллективным эффектом. И в самом деле, выживать в одиночку обычно сложнее, чем в коллективе, члены которого могут помогать друг другу. Поэтому основным фактором, сокращающим смертность, является взаимопомощь, т.е. форма коллективного поведения, повышающая шансы на выживание каждой отдельной особи.

В математической экологии увеличение индивидуальной приспособленности по мере роста численности или плотности популяции известно как эффект Олли [Courchamp et al. 2008]. Он может быть связан как с чисто биологическими факторами (повышение генетического разнообразия, облегчение поиска половых партнеров, улучшение условий окружающей среды), так и с собственно коллективным поведением. В популяциях животных оно выражается главным образом в стайной охоте и миграции, совместной защите от хищников и заботе о потомстве. Для человека спектр форм взаимопомощи становится много шире, пополняясь передачей накопленного опыта от стариков к молодым, преобразованием неосвоенных территорий, обменом товарами и знаниями, а также возможностью профессиональной специализации и разделения социальных функций членов популяции. Люди в отличие от животных не ограничены инстинктивными схемами коллективного поведения и вырабатывают гибкие формы взаимопомощи, эффективно использующие имеющуюся численность.

Рассмотрим для примера ситуацию встречи человека с крупным хищником. Если человек один, то он, скорее всего, просто будет съеден. Однако если людей десяток, то часть из них разбежится и уцелеет, в то время как сотня уже сумеет отбиться. Для тысячи человек не составит труда организовать охрану своего поселения, а для десяти тысяч сформировать отряды для охоты на зверя. Сто тысяч человек изведут всех его собратьев в округе, а если и не всех, то, дойдя количеством до миллиона, переловят оставшихся для зоопарка... Иными словами, в зависимости от количества людей меняется их реакция на конкретную опасность и относительный уровень потерь от нее. Будь человек животным, описанная цепочка оборвалась бы где-то на десятке-сотне особей, а так ее легко можно продолжить и далее вплоть до борьбы за сохранение хищника как вымирающего вида.

В то время как формы коллективного поведения, доступные животным, предполагают конкретный перечень действий, для каждого из которых имеется оптимальный размер популяции, взаимопомощь людей тем эффективнее, чем их больше. Человек разумен, вследствие чего способен расширять спектр видов взаимопомощи, адаптируя их к новым ситуациям и сокращая смертность по мере роста своей численности. В этом заключается принципиальное отличие человека от животных, которое можно рассматривать как определение разума на уровне вида. Единственная задача любого биологического вида - преумножать свою численность. И человек справляется с этой задачей качественно лучше животных. 
Увеличение количества людей обусловлено тем, что остаются живы те, кто умер бы, не будь взаимопомощи. А рост народонаселения в свою очередь приводит к дальнейшему усилению ее роли и снижению смертности.

\section{Концепция жнзнесберегающих технологий}

Высказанные соображения, дающие принципиальное объяснение феномена роста народонаселения, в неизменном виде не могут быть положены в основу демографической теории. Они применимы лишь для отдельной популяции и не допускают прямого обобщения на всё человечество, которое, будучи целостной системой, не сводимо к сумме своих частей. Кроме того, начиная с определенного количества людей, непосредственная взаимопомощь оказывается затруднена, так как человек способен участвовать лишь в ограниченном числе социальных связей.

Чтобы отдельные людские популяции могли составлять единое человечество, между ними должно быть какое-то взаимодействие, переносчик которого способен свободно проникать сквозь географические, политические и культурные барьеры, не расходуясь при взаимодействии. Необходимыми свойствами обладают технологии, т.е. знания, которые, будучи однажды обретенными, уже не утрачиваются, так как их распространение и тиражирование дается намного легче, чем создание.

Термин «технологии» здесь понимается предельно широко и включает в себя не только способы хозяйствования, но и государственное управление, воинское искусство, религиозные доктрины, средства коммуникаций, торговлю, медицину и вообще любые знания и навыки, которые могут быть использованы для спасения человека от смерти или продления его жизни. Такие знания предлагается именовать жизнесберегающими технологиями.

Жизнесберегающие технологии имеют принципиальное отличие как от информации вообще, так и от технологий в узкоинженерном смысле этого слова. Любая информация постепенно теряется, и выжить во времени могут только те знания, которые жизненно необходимы и потому постоянно используются и тем самым возобновляются. Касаясь всех и являясь делом каждого, жизнесберегающие технологии не требуют для своего создания и распространения какого-то специального механизма.

Прежде чем перейти к изложению теории глобального демографического процесса, опирающейся на представление о жизнесберегающих технологиях, необходимо высказать одно простое соображение. Учет деталей при рассмотрении любой задачи целесообразен лишь в той мере, в какой мы знаем фундаментальные закономерности. Соответственно, при поиске этих закономерностей от деталей можно и должно отрешиться.

Характеризуя популяцию единственно ее численностью $n$ и не принимая во внимание ни различие людей по возрасту и полу, ни пространственную структуру их расселения, мы аналогично огрубленным образом будем описывать и жизнесберегающие технологии, считая, что уровень их развития может быть охарактеризован одним числом $p$. При этом мы не задаемся вопросом, как определить его значение на основе каких-либо данных об имеющихся технологиях. 
Жизнесберегающие технологии создаются людьми в процессе их повседневной деятельности, осуществляемой на основе уже имеющихся технологий. Соответственно, для скорости их появления можно записать кинетическое уравнение:

$$
\dot{p} \sim p n \text {. }
$$

Следует предостеречь от суженной трактовки уравнения (4) как результата исключительно действия «изобретателей» - людей, составляющих определенную часть населения и специализирующихся на совершенствовании технологий. Профессиональная специализация сама по себе является жизнесберегающей технологией, развитие которой и выражается в изменении доли таких людей.

Аналогичным образом распространение новых технологий из активно развивающихся центров тоже следует рассматривать как жизнесберегающую технологию. Ее действие снимает необходимость повторно изобретать одно и то же в разных местах или дожидаться, пока местных жителей вытеснят носители передовых технологий.

Наконец, освоение новых территорий и расширение ареала обитания также является результатом технологического развития, позволяющим добраться до земель, которые ранее были непригодны для обитания, и выжить там.

\section{Технологический императив}

В дикой природе средняя численность любого вида животных определяется размером занимаемой им экологической ниши, т.е. тем количеством особей, выживание которых может обеспечить вмещающая вид территория.

Аналогичным образом численность человечества определяется размером созданной им технологической ниши, т.е. тем количеством людей, которые могут быть востребованы созданными ими технологиями:

$$
n=f(p) .
$$

Данное утверждение, постулирующее первичность технологических факторов по отношению к демографическим, назовем технологическим императивом, рассматривая его как принципиальную конкретизацию демографического императива.

Запись формулы (5) в виде алгебраического, а не дифференциального уравнения означает, что при изменении размера ниши подстройка численности происходит очень быстро, поэтому можно считать, что между $n$ и $p$ имеется функциональная связь.

В нормальной ситуации количество людей, выживание которых жизнесберегающие технологии могут обеспечить, совпадает с тем количеством людей, которое необходимо для функционирования этих технологий.

Если в силу действия каких-либо возмущающих факторов имеющиеся технологии более не могут обеспечить выживания всех востребованных ими людей, то происходит отказ от наименее эффективных и наиболее трудоемких технологий, т.е. сокращение 
размера технологической ниши. Обратная ситуация, когда обеспечивается выживание большего количества людей, чем может быть востребовано, разрешается посредством значительных исторических событий (войны, смуты, крестовые походы, массовая миграция и др.), приводящих число живущих людей в соответствие с размером технологической ниши.

И структура технологий, и система расселения людей по своей природе иерархичны, а сами технологии и поселения масштабируемы в диапазоне нескольких порядков величины. Поэтому разумным представляется предположение, что в фазе роста ни одна из входящих в формулу (5) переменных не имеет характерных значений и, следовательно, функция $f(p)$ однородна, т.е.:

$$
n \sim p^{\gamma}
$$

Дифференцирование формулы (6) с последующим исключением переменной $p$ посредством формулы (4) приводит к квадратичной зависимости скорости роста от населения вида (2), ранее полученной на основе анализа демографических данных. Таким образом, данная зависимость оказывается обусловлена технологической природой роста.

\section{Базовая модель роста}

Система (4)-(6) инварианта относительно невырожденных преобразований вида $p \rightarrow \mu p^{v}$, допускающих большую свободу выбора шкалы измерения жизнесберегающих технологий. Можно подобрать такие значения параметров $\mu$ и $v$, что система уравнений примет вид:

$$
\begin{aligned}
& \dot{p}=p n / C, \\
& n=C p
\end{aligned}
$$

с одним и тем же параметром $C$, допускающим двоякую интерпретацию.

Во-первых, как следует из формулы (7), величина $C$, равная количеству человеколет, необходимому людям для увеличения своего технологического уровня в $e$ раз в условиях постоянной численности, определяет демографическую цену прогресса. А вовторых, формула (8) позволяет трактовать $C$ как емкость технологической ниши коэффициент пропорциональности между уровнем развития технологий и востребованной ими численностью населения.

Еще больше смыслов имеет величина $p$. Исключив с помощью формулы переменную $n$ из закона роста населения (1), получаем закон роста технологий:

$$
p(t)=1 / \Delta t,
$$

позволяющий интерпретировать их уровень как обратную постоянную времени. Т.е. именно технологическое развитие определяет сжатие исторического времени, ускоряющегося по мере приближения к моменту обострения. Дифференцируя эту формулу, 
приходим к уравнению:

$$
\dot{p}=p^{2},
$$

снимающему кажущееся противоречение между принципиально дискретным характером технологического развития и его непрерывным описанием, каковое может рассматриваться только как осреднение. Предположим, что развитие человечества застопорилось из-за того, что оно столкнулось с некоторым технологическим барьером высоты $\delta p$, для преодоления которого требуется совершить определенную новацию. На это требуется время $\delta t$, для которого с помощью формул (9) и (10) находим $\delta t / \Delta t \cong \delta p / p$. Относительная высота барьера, стоящая в правой части этого соотношения, примерно постоянна. Она может быть грубо оценена десятыми или сотыми долями, так как меньший барьер не послужил бы причиной задержки в развитии, а больший - не мог бы быть преодолен. Соответственно, и дискретность развития становится несущественной при его рассмотрении на временах, отношение которых к $\Delta t$ уже соизмеримо с указанной величиной, но на которых непрерывное описание еще является достаточно точным.

\section{Естественная икала технологий и пределы роста}

Исключение из системы (7)-(8) не численности населения $n$, а константы $C$ порождает уравнение:

$$
\dot{n}=p \cdot n,
$$

объясняющее, почему гиперболический закон вида (1) оказывается, по крайней мере, приближенно применим к численности населения не только всего мира, но также отдельных регионов и даже стран. Если с некоторой точностью можно считать, что они характеризуются тем же самым технологическим уровнем, что и мир в целом, то для них скорость роста населения линейно зависит от его численности с одним и тем же коэффициентом (9).

Наконец, формула (11) может рассматриваться как уравнение мальтузианского роста с темпами $p=b-d$, где $b$ и $d$ - общие коэффициенты рождаемости и смертности. Считая в фазе роста рождаемость неизменной, можно записать $b=b_{0}=d_{0}$, где нолик означает значения коэффициентов на момент начала роста, когда еще смертность уравновешивала рождаемость. Таким образом:

$$
p=d_{0}-d,
$$

т.е. уровень развития жизнесберегающих технологий равен связанному с ним уменьшению коэффициента смертности. Иными словами, шкала, выбранная из соображений простоты уравнений, оказывается для жизнесберегающих технологий естественной. Вместо того чтобы пытаться учесть весь массив технологий и взаимосвязи между ними, мы измеряем уровень технологического развития по производимому эффекту, определяемому долей людей, которых удается спасти от смерти в единицу времени. 
Данный результат оправдывает предположение о возможности охарактеризовать различные аспекты технологического развития одним числом. Точно так же, как в экономике фигурируют деньги как естественный скаляризатор, сводящий матрицу меновых стоимостей к вектору цен, так и в теоретической демографии фигурируют жизнесберегающие технологии как такой же естественный скаляризатор, сводящий все виды человеческой деятельности к количеству сохраненных жизней.

Формула (12) позволяет легко объяснить причины демографического перехода и оценить предель технологического и демографического роста $p_{\infty}$ и $n_{\infty}$.

Величину коэффициента смертности первобытного человека можно оценить как $d_{0} \approx 0,06$ год ${ }^{-1}$ на основе кривой выживания шимпанзе [Ичас 1994], являющейся нашим ближайшим родственником среди ныне существующих видов.

Предельный коэффициент смертности можно ориентировочно оценить как $d_{\infty} \approx(0,01 \pm 0,01) г о^{-1}$, где базовое значение соответствует уровню, к которому эта величина приближается сейчас в наиболее развитых странах, а разброс буквально описывает диапазон от зверя до бога. Если бы при возникновении вида Homo sapiens максимальная продолжительность жизни наших предков осталась на обезьяньем уровне (примерно 50 лет [Ичас 1994]), а не увеличилась вдвое, то мы бы имели для погрешности знак «+», а если люди когда-нибудь станут бессмертными, как боги, то мы возьмем для нее знак «-».

Таким образом, имеется предел развития жизнесберегающих технологий, равный $p_{\infty}=d_{0}-d_{\infty} \approx(0,05 \pm 0,01)$ год ${ }^{-1}$. Его наличие ни в коем случае не ограничивает возможности технологического развития вообще. Однако создаваемые технологии становятся всё менее эффективными (по отношению, скажем, к их экономической значимости или инженерной сложности) с точки зрения спасения жизней и тем самым вносят всё меньший вклад в величину $p$.

Как следует из формулы (8), предельная численность человечества составляет $n_{\infty}=C p_{\infty} \approx(10 \pm 2)$ млрд чел. Особо подчеркнем, что ни конкретное значение, ни даже само существование этой величины никак не связаны с какими бы то ни было ограничениями материального плана, а обусловлены исключительно природой демографического процесса. В силу невозможности опустить смертность ниже нуля человек не может развить жизнесберегающие технологии, которые востребовали бы большее количество представителей вида. К исчерпанию близятся не запасы полезных ископаемых, жизненного пространства или неосвоенных рынков, а потенциал снижения смертности, т.е. тот единственный ресурс, освоение которого и обеспечивало прогресс цивилизации.

\section{Модель Кремера}

Описанная модель была построена автором много лет назад как полемическое развитие идей С.П. Капицы. Впоследствии автор познакомился с классической работой [Kremer 1993], в которой приводится математически схожий вывод уравнения (2), также опирающийся на представление о технологиях. 
Принципиально, однако, что М. Кремер рассматривает технологии исключительно как фактор производства, обеспечивающий необходимый для выживания душевой доход. Такая трактовка технологического развития делает его потенциально безграничным. Поэтому приходится искусственно класть пределы численности населения - введением в модель немонотонной зависимости темпа его прироста от душевого дохода. При этом ни количественного описания, ни хотя бы качественного объяснения для этой зависимости не приводится, лишь высказывается предположение, что она может быть обусловлена возрастанием стоимости детей, рассматриваемым как данность.

Подобные непреодолимые трудности экономоцентрического подхода лишний раз демонстрируют несводимость глобального демографического процесса к факторам, которые возникают лишь на определенных его этапах. Производство и экономические отношения, будучи сравнительно поздним изобретениями человечества, не могут отвечать за его развитие на более ранних этапах.

\section{ФЕНОМЕНОЛОГИЧЕСКАЯ МОДЕЛЬ ДЕМОГРАФИЧЕСКОГО ПЕРЕХОДА}

Итак, мы знаем, почему растет население, и знаем, как оно растет. Мы знаем, почему прекращается рост, но не знаем, как именно это происходит.

К сожалению, пока не сформулированы те первые принципы, из которых можно было бы строго вывести формулы, описывающие демографический переход. Поэтому вместо построения математической модели этого явления можно попытаться предложить только феноменологическую модель, т.е. угадать ключевые факторы, которые надо включить в нее во что бы то ни стало, и выписать для них из общих соображений такие формулы, которые бы обеспечили согласие с реальностью. При этом мы будем руководствоваться принцииами соответствия и простоты, т.е. новая модель должна сводиться к старой в фазе роста и привлекать минимальное количество дополнительных параметров для описания демографического перехода.

\section{Построение модели}

Ключевыми обстоятельствами, отражение которых абсолютно необходимо, представляются наличие естественного предела технологического развития и изменение возрастной структуры населения в результате снижения смертности.

Для учета первого из указанных факторов мы модифицируем уравнение (7), записав его в следующем виде:

$$
\dot{p}=p n / C \cdot\left(1-p / p_{\infty}\right) .
$$

Такая запись не использует дополнительных параметров, т.е. является простейшей, обеспечивающей ограниченность технологического роста. Кроме принципа простоты, нет никаких причин, почему в формуле (13) нельзя было бы, скажем, возвести скобку или, тем более, вычитаемое в ней в некоторую степень. Однако удовлетворительное совпадение поведения модели с демографическими данными делает подобные усложнения излишними. 
Второй из названных выше факторов сказывается на зависимости размера технологической ниши от уровня технологий. В результате формула (8) получает дополнительный множитель:

$$
n=C p \cdot g(p),
$$

где функция $g(p)$ имеет вид $S$-образной кривой, плавно изменяющей свое значение от одного константного уровня до другого. Тем самым учитывается переход от треугольной возрастной пирамиды к прямоугольной.

Треугольная возрастная пирамида обусловлена высокой смертностью во всех возрастах, в том числе в молодых, из-за чего с возрастом быстро сокращается доля доживших до него людей. По мере снижения смертности действие ее причин отодвигается к старшим возрастам, в силу чего доля людей, переживших детство, юность и даже зрелось, приближается к единице, а почти все смерти приходятся на старость, что и выражается в прямоугольном виде возрастной пирамиды.

Уровень жизнесберегающих технологий измеряется изменением коэффициента смертности, достигнутым в результате их развития, поэтому его значение для конкретного интервала возрастов (детства и юности) можно приблизить линейной функцией $p$, параметры которой для простоты будем считать постоянными. Тогда вероятность пережить этот интервал возрастов (и дожить до зрелости) будет зависеть от $p$ экспоненциальным образом. При этом изменение числа выживших приближенно описывается дробнолинейной функцией этой вероятности:

$$
g(p)=1+\frac{a}{1+e^{-\alpha\left(p / p_{\infty}-\beta\right)}},
$$

имеющей три параметра, что является очевидным минимумом, так как при описании любого перехода необходимо указать, в какой момент $(\beta)$, как быстро $(\alpha)$ и на сколько $(a)$ происходит изменение. Вновь обращаясь к принципу простоты, мы считаем функцию (15), описывающую переход, симметричной, чтобы не вводить дополнительных параметров для учета асимметрии.

\section{Анализ модели}

Как можно видеть из таблицы 1 , значения параметров $C$ и $n_{\infty}$, найденные посредством подгонки предсказаний модели (13)-(14)-(15) к реальным данным (см. далее), оказываются близки к значениям этих величин, использовавшимся в модели (7)-(8). Вместе с тем эти модели характеризуются заметно различающимся значениями параметра $p_{\infty}$. Данное обстоятельство обусловлено тем, что трактовка жизнесберегающих технологий и количественное определение их уровня, неизмеримого непосредственно, существенным образом зависят от используемой модели. 
Таблица 1. Параметры моделей демографических роста и перехода

\begin{tabular}{l|c|r|r}
\hline Величина & Рост & Переход & Единицы \\
\hline$C$ & 200 & 190,1 & млрд чел.год \\
$n_{\infty}$ & 10 & 10,16 & млрд чел. \\
$p_{\infty}$ & & 0,0354 & год $^{-1}$ \\
$n_{\infty} / C$ & 0,05 & 0,0535 & \\
$a$ & & 0,510 & \\
$\alpha$ & - & 21,12 & \\
$\beta$ & - & 0,376 & г. \\
$t_{f}$ & - & 2023,5 & \\
\hline
\end{tabular}

Уменьшение величины $p_{\infty}$ связано с возрастающим характером функции (15), означающим рост емкости технологической ниши во время демографического перехода, что составляет суть этого явления с точки зрения технологического императива. Изменение возрастной структуры приводит не к уменьшению числа востребованных технологиями людей за счет повышения доли взрослых, как можно было бы ожидать, а к возможности для «лишних» взрослых найти себе место в технологической нише. Раньше таких людей в популяции просто не могло появиться, поэтому не существует и механизмов их исключения или недопущения их появления, хотя весьма вероятно возникновение таких механизмов в будущем. В этом случае сценарий стабилизации численности человечества сменится сценарием ее убывания, что потребует доработки модели, для чего, однако, пока нет надежных наблюдательных данных.

Переход от линейной формулы (8) к нелинейной (14) размывает физический смысл величины $C$. Она более не может однозначно интерпретироваться как постоянная емкость технологической ниши. Вместо этого уместно ввести две функщиии емкости - интегральной и дифференциальной:

$$
C_{\text {int }}(p)=\frac{n}{p}=C \cdot g(p), C_{\text {diff }}(p)=\frac{d n}{d p}=C \cdot\left[g(p)+p g^{\prime}(p)\right],
$$

динамика которых представлена на рисунке 4. Обе этих функции по ходу прогресса изменяются от $C$ до $C(1+a)$. Однако если интегральная емкость описывает монотонное увеличения размера технологической ниши, то дифференциальная показывает, как и когда происходила перестройка возрастной структуры населения.

Поскольку $\alpha>>1$ (см. таблицу 1), экспонента в формуле (15) пробегает практически всю положительную полуось. Поэтому модель легко исследуется в предельных случаях, когда функция $g(p)$ примерно постоянна: $g(p) \approx 1$ при $p<<\beta p_{\infty}$ и $g(p) \approx 1+a$ при $p>>\beta p_{\infty}$. В первом случае модель ожидаемо сводится к уравнению (2), а во втором упрощается до записи:

$$
\frac{d n}{d t}=\frac{n^{2}}{C} \cdot\left(1-\frac{n}{n_{\infty}}\right),
$$


где $n_{\infty}=C(1+a) p_{\infty}$. Неявное решение этого уравнения может быть найдено аналитически:

$$
\frac{n_{\infty}}{n(t)}+\ln \left(\frac{n_{\infty}}{n(t)}-1\right)=\frac{\Delta t}{\tau}
$$

что дает экспоненциальный асимптотический режим при $n \rightarrow n_{\infty}$ :

$$
n_{\infty}-n(t) \cong n_{\infty}\left(1-e^{\Delta t / \tau-1}\right)
$$

с характерным временем $\tau=C / n_{\infty}$.

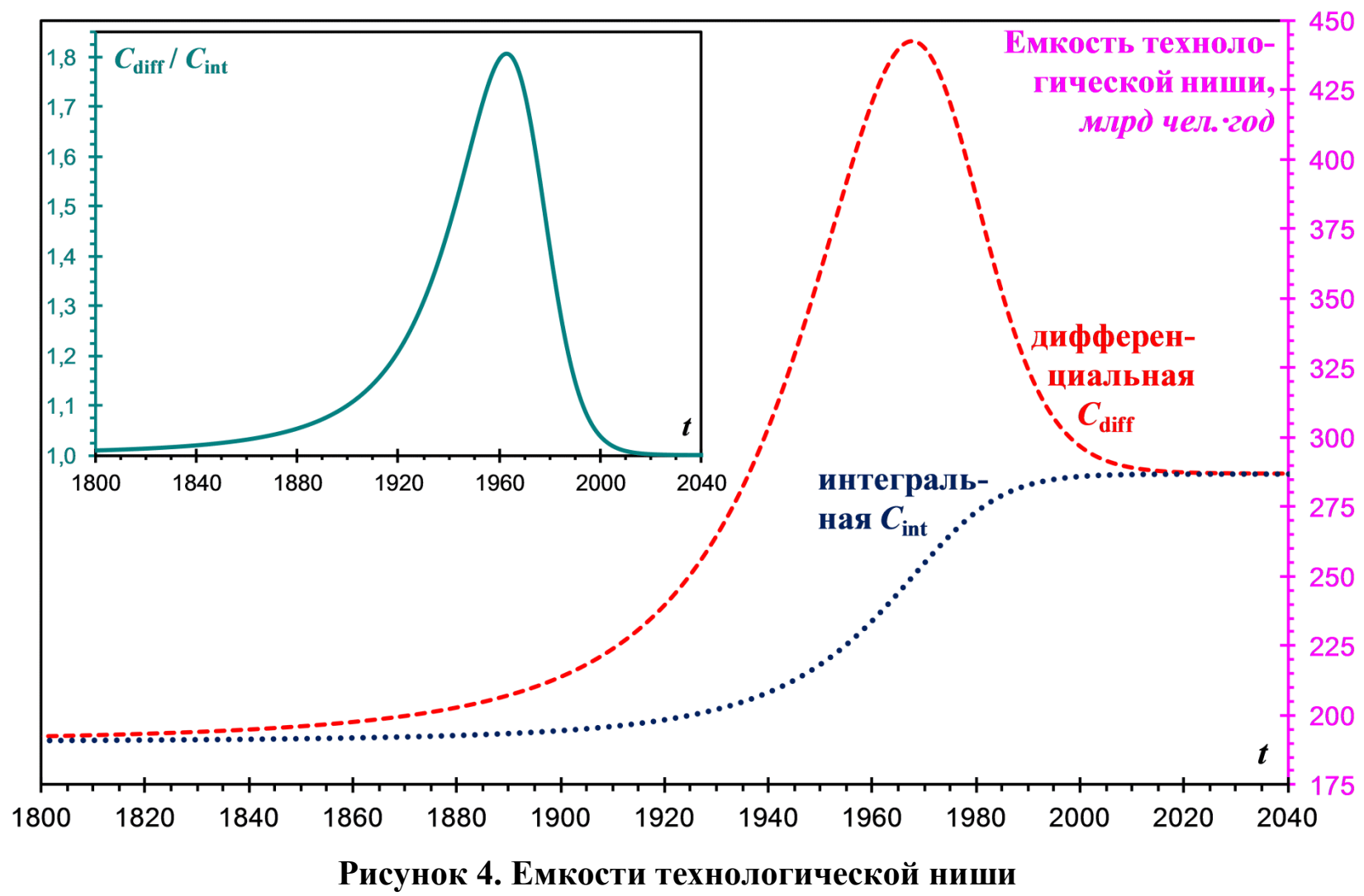

Примечание: Дифференциальная емкость имеет те же асимптотические предель, что и интегральная, однако демографический переход сопряжен с кратковременным взлетом ее значения. Он практически совпадает с моментом максимальных темпов прироста.

На врезке - отношение емкостей, всплеск которого отмечает период сильной нелинейности в зависимости численности населения от уровня технологий.

\section{Альтернативные модели}

Ранее различными авторами уже предпринимались несколько попыток построить феноменологические модели демографического перехода. Наиболее известны среди них модели Капицы [Капица и др. 1997; Капица 1999] и Коротаева-Малкова-Халтуриной [Коротаев и др. 2007], которые мы тоже опишем и кратко проанализируем до сопоставления их результатов с реальностью. 
Для этих моделей была выполнена такая же подгонка к реальным данным, что и для предлагаемой в настоящей работе модели. Чтобы поставить все модели в одинаковые условия, приводимые далее графики построены с использованием именно таких значений параметров, а их значения, предложенные авторами моделей, приводятся в таблицах далее только для справки.

\section{Модель Капицы}

С.П. Капица из соображений простоты формул предложил следующую феноменологическую зависимость скорости роста населения от его численности:

$$
\frac{d n}{d t}=\frac{n_{\infty}}{\tau} \cdot \frac{1}{\pi} \sin ^{2} \pi \frac{n}{n_{\infty}}
$$

переходящую в уравнение (2) при $n<<n_{\infty}=\pi C / \tau$. Точное решение уравнения (17) может быть записано явным образом и имеет вид $n(t)=n_{\infty} / \pi \cdot \operatorname{arcctg} \Delta t / \tau$. При $n<<n_{\infty}$ оно превращается в закон роста (1), а асимптотическое поведение решения при $n \rightarrow n_{\infty}$ дается аналогичной безмасштабной формулой:

$$
n_{\infty}-n(t) \cong C / \Delta t .
$$

Таблица 2. Параметры модели Капицы

\begin{tabular}{l|r|r|r}
\hline Величина & Автор & Подгонка & Единицы \\
\hline$n_{\infty}$ & 12,92 & 12,34 & млрд чел. \\
$\tau$ & 45,0 & 43,7 & год \\
$t_{f}$ & 2005 & 2000 & г. \\
\hline
\end{tabular}

Параметры модели, предложенные ее автором и полученные подгонкой к демографическим данным в рамках настоящей работы, сведены в таблице 2.

\section{Модель Коротаева-Малкова-Халтуриной}

А.В. Коротаев, А.С. Малков и Д.А. Халтурина предложили модель, сводящуюся к системе уравнений:

$$
\left\{\begin{array}{l}
\dot{n}=n \cdot s \cdot\left(1-\left(n / n_{\infty}\right)^{z}\right), \\
\dot{s}=s / \tau \cdot n / n_{\infty}
\end{array}\right.
$$

где переменная $s$ характеризует экономическое развитие в условных единицах, $\tau$ некоторая постоянная времени, $z$ - нетривиальный показатель, смысл которого авторами модели не поясняется, а природа предельной численности $n_{\infty}$ связывается ими с достижением населением 100\%-ной грамотности. Параметры модели приведены в таблице 3. 
Таблица 3. Параметры модели Коротаева-Малкова-Халтуриной

\begin{tabular}{l|c|c|c}
\hline Величина & Авторы & Подгонка & Единицы \\
\hline$n_{\infty}$ & 8,50 & 9,43 & млрд чел. \\
$n_{\min }$ & 142 & 129 & млн чел. \\
$z$ & 0,755 & 0,695 & \\
$\tau$ & 18,1 & 17,8 & год \\
$t^{*}$ & 1999 & 2008 & г. \\
$s\left(t^{*}\right)$ & $8,78 \%$ & $9,69 \%$ & год \\
\hline
\end{tabular}

Система (19) может быть решена в квадратурах делением первого ее уравнения на второе:

$$
\tau \cdot d s=\frac{d n / n_{\infty}}{1-\left(n / n_{\infty}\right)^{z}}
$$

И хотя данное уравнение не интегрируется в элементарных функциях, легко находятся его решения для предельных случаев.

При $n<<n_{\infty}$ величины $s$ и $n$ связаны просто линейной зависимостью: $n=n_{\min }+n_{\infty} \tau s$, где $n_{\min }$ - численность населения при нулевом экономическом развитии.

Подстановка этой формулы в первое уравнение системы показывает, что в пределе малой численности она переходит в уравнение (2) только при специальном подборе параметров (при $\left.n_{\min }=0\right)$. Нарушение моделью Коротаева-Малкова-Халтуриной принципа соответствия приводит к тому, что она де-факто трактует демографический рост как пороговый эффект. Темп прироста населения, примерно равный $s$, при $n<n_{\text {min }}$ должен был бы быть отрицательным в силу отрицательности $s$.

Примечательно, что если бы реальный рост населения не отклонялся от закона (1), население достигло бы численности $n_{\min }$ еще в середине VI или начале VII века при авторских и подгонных параметрах соответственно. Реально же эта численность была достигнута чуть раньше - в конце старой эры. Из того, что $n_{\min }$ превышает $n_{0}$ более чем на 3 порядка (см. таблицу 3 и формулу (3)), можно заключить, что модель КоротаеваМалкова-Халтуриной способна описывать лишь очень малую долю протяженности демографического процесса.

В другом пределе - при $n \rightarrow n_{\infty}$ - решение системы тоже может быть получено в элементарных функциях и подчиняется формуле:

$$
n_{\infty}-n(t) \sim e^{-\frac{t-t^{*}}{\tau}},
$$

означающей столь стремительное приближение населения к асимптоте, что в численных расчетах его выход на константу можно считать происходящим за конечное время. И случиться это должно еще в первой половине XXI века, что представляется абсолютно нереалистичным. 


\section{Определение параметров моделей}

Для подбора параметров моделей рассматривается зависимость темпа прироста населения от его численности. Данная пара величин выгодно отличается от всех прочих пониженной чувствительностью к разного рода флуктуациям, которыми изобилует фаза роста (изменения климата, войны, эпидемии, переселения народов). Поскольку в это время темп прироста населения был приблизительно пропорционален его численности, такие воздействия лишь сдвигали точки вдоль графика, в минимальной степени нарушая его вид.

Учитывая, что процедура численного дифференцирования неустойчива, a результаты подгонки многопараметрических моделей могут быть весьма чувствительны к используемому эталону, опишем методику его получения в деталях.

Сколь-нибудь подборные демографические данные по всему миру до середины $\mathrm{XX}$ века отсутствуют. Поэтому для построения реальной зависимости темпов от населения использовался временной ряд его численности, взятый из работы [Kremer 1993]. В связи с тем, что точки здесь весьма редки, а диапазон изменения величин и их погрешности чрезвычайно велики, использовался следующий метод фильтрации. Рассматривалась зависимость населения от времени до момента обострения в двойных логарифмических координатах $\ln n(t)=h(\ln \Delta t)$, аналогичная показанной на рисунке 3. Дифференцирование этой зависимости выражает темп прироста населения через ее локальный наклон:

$$
\frac{d n}{n d t}=\frac{h^{\prime}(\ln \Delta t)}{\Delta t}
$$

который определялся с помощью линейной регрессии по 5 точкам. Соответствующие значения $n$ и $\Delta t$ рассчитывались усреднением их логарифмов по тем же точкам и потенциированием результатов.

Начиная с середины XX века появляется регулярная демографическая статистика. В настоящей работе использовались данные Бюро переписей населения США [Total midyear population], дающие ежегодные данные о мировом населении и прогноз его динамики на интервале 1950-2050 гг. Темп прироста определялся как угловой коэффициент линейной регрессии, описывающей зависимость $\ln n$ от $t$ в 15 -тилетнем окне, а в качестве оценки численности населения бралась ее величина из середины окна.

Как можно видеть из рисунка 5, в окрестности 1950 г. графики темпов, полученные обоими способами, оказываются достаточно близки, что позволяет сшить их в этой точке. 


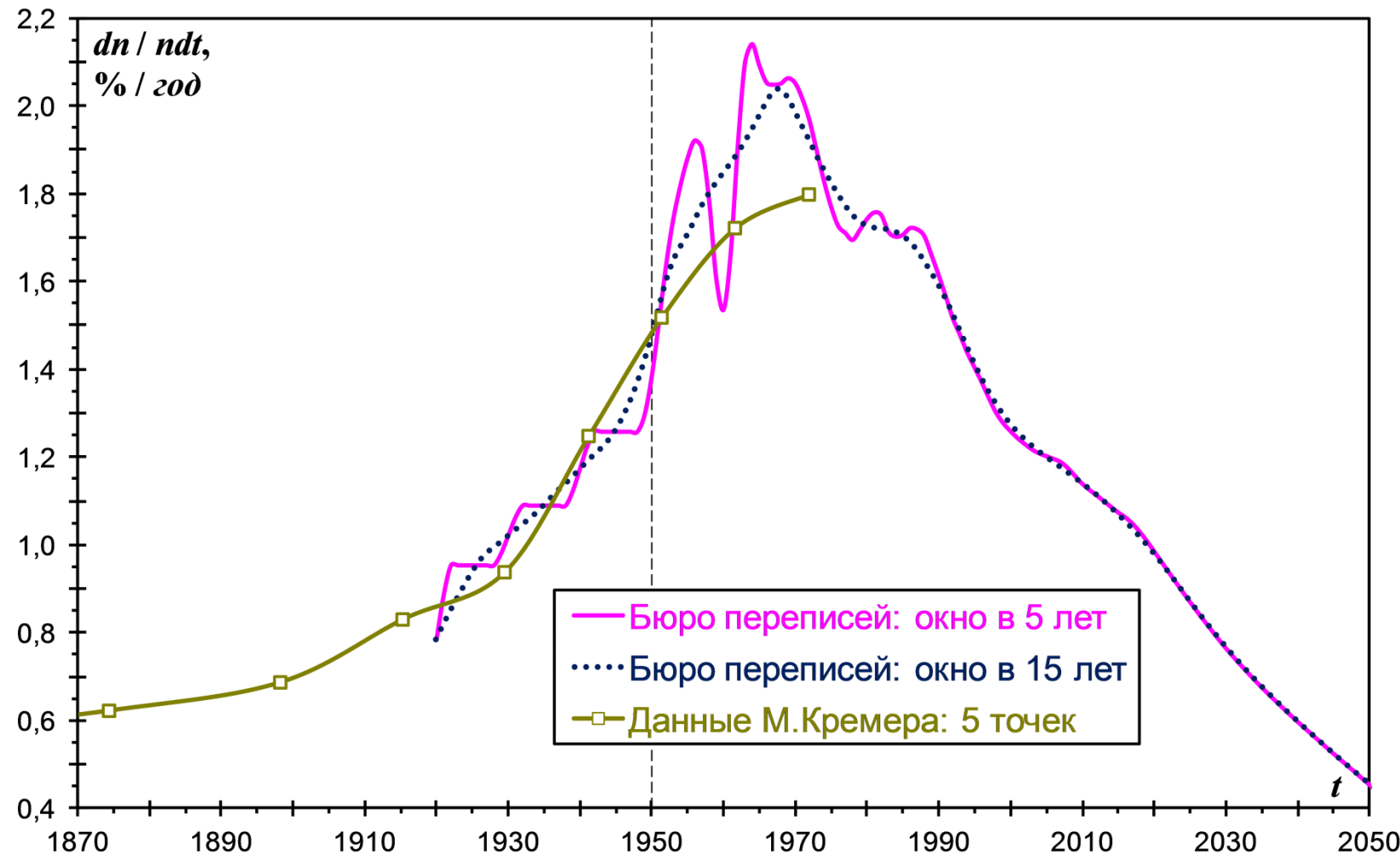

Рисунок 5. Сшивка графиков темпов прироста населения

Примечание: Сшивка производится по 1950 2., начиная с которого используются данные Бюро переписей, сглаженные в 15-тилетнем окне, а до него - данные М. Кремера. Для исключения краевых эффектов данные Бюро переписей до 1950 г. экстраполированы линейной регрессией на основе ряда М. Кремера, а прогнозы темпов после 2050 г. - линейной регрессией по времени.

Различие между графиками, полученными в 5-ти- и 15-тилетнем окнах, определяет требования по точности, которые следует предъявлять к моделям. Отклонение темпов от реальности менее 0,05 процентного пункта следует считать хорошим результатом, а менее 0,1 процентного пункта удовлетворительным.

\section{Сравнение моделей}

Рисунок 6 демонстрирует разительные качественное и количественное отличия моделей Капицы и Коротаева-Малкова-Халтуриной как от реальности, так и от модели автора, заставляющие отдать предпочтение последней. Только она может воспроизвести такие важные особенности демографической динамики, как постоянство среднегодового прироста населения на широком диапазоне его значений, прохождение которого увеличивает человечество примерно на 4 млрд человек, и отчетливо выраженный максимум зависимости темпов прироста населения от его численности, достигаемый при еще сравнительно небольшом ее значении в 3,5 млрд человек.

Также обращает на себя внимание принципиально разный вид графиков в правых частях рисунка 6, которые для модели Капицы подходят к оси ординат горизонтально, для модели Коротаева-Малкова-Халтуриной - вертикально, а для предлагаемой модели - под некоторым нетривиальным углом. В ней население приближается к асимптотическому пределу $n_{\infty}$ с характерным временем, которое имеет конечное значение (16), тогда как в модели Капицы оно бесконечное (18), а в модели Коротаева-Малкова-Халтуриной 
эффективно нулевое (20). С этой точки зрения поведение классических моделей следует считать вырожденным.
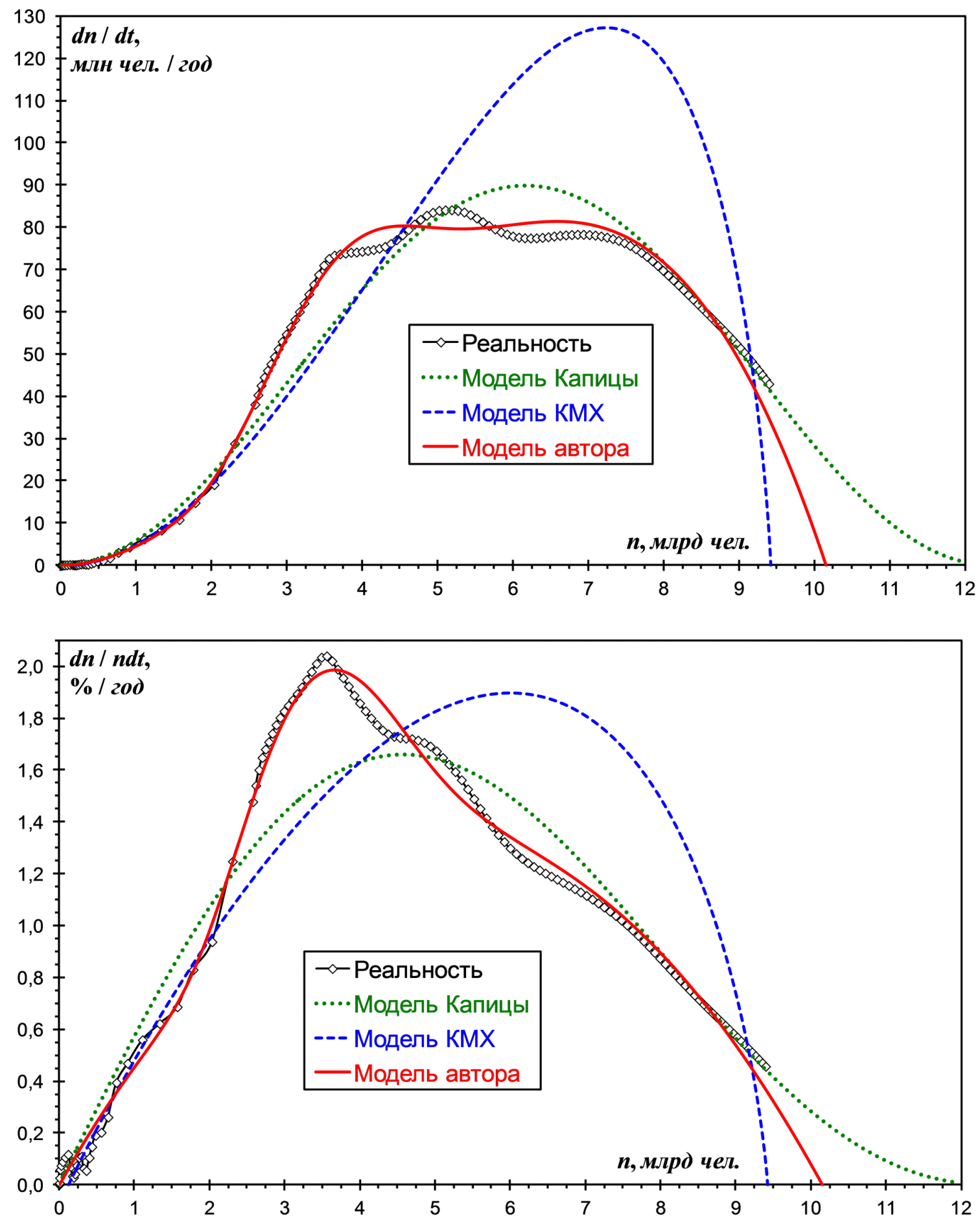

Рисунок 6. Сравнение фазовых портретов моделей

Примечание: Ни одна из классических моделей не может приблизить реальные графики прироста и его темпов, тогда как соответствие динамики авторской модели реальным данным следует признать удовлетворительным.

Отчасти реабилитирует модели Капицы и Коротаева-Малкова-Халтуриной рисунок 7, демонстрирующий зависимость населения от времени на масштабе 3,5 mblc. лет. На большей части этого графика флуктуации сильнее сказываются на населении, чем его 
естественный рост, а на той меньшей части, где флуктуации уже несущественны, рост столь значителен, что его особенности практически неразличимы.

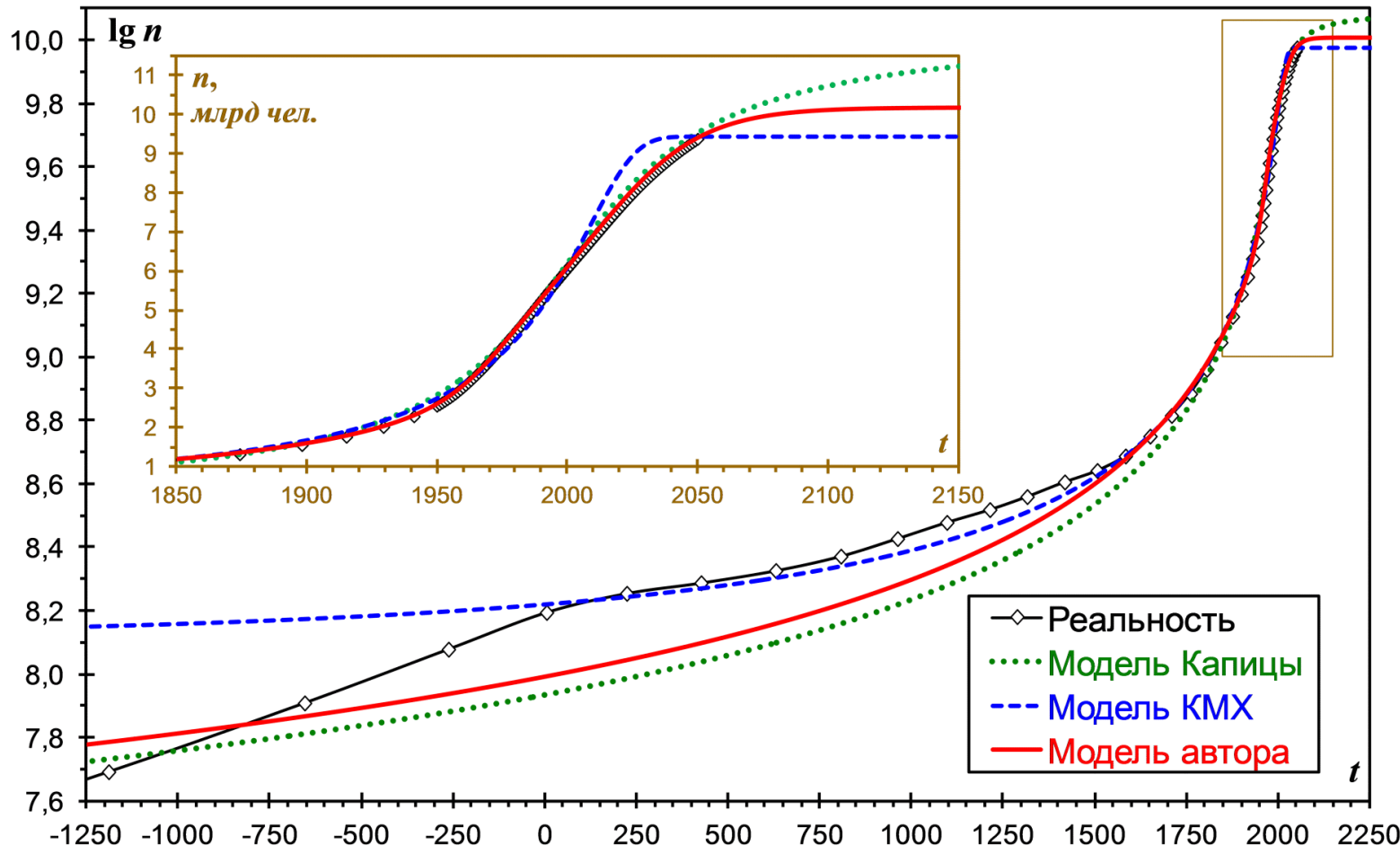

Рисунок 7. Сравнение динамики населения по моделям

Примечание: Все рассмотренные модели для XIX-XX веков обеспечивают удовлетворительное приближение реальных данных. А модель Коротаева-Малкова-Халтуриной согласуется с ними на протяжении всей новой эры, включая римский (I-IV века) и средневековый (X-ХIII века) климатические оптимумы, девиантный характер численности населения во время которых отчетливо виден на рисунке 3. Модели Капииь и автора не обладают способностью так хорошо воспроизводть последствия климатических флуктуачий, давая сильно заниженнье значения численности во время климатических оптимумов, но лучше отслеживая общий тренд.

На врезке увеличен обведенный рамкой участок. На нем предсказания моделей Капицы и автора практически не отличаются от реальности, тогда как в модели Коротаева-Малкова-Халтуриной населению приходится расти слишком быстро, чтобы успеть выйти на константу за конечное время, что приводит к заметным отличиям предсказаний этой модели от реальности.

Поведение моделей на стадии демографического перехода и их прогноз на ближайшее будущее представлены на врезке рисунка 7, которая ограничена масштабом трех веков. Как можно видеть, модель автора занимает промежуточное положение между классическими моделями, предсказывая не столь быстрое прекращение роста населения, как модель Коротаева-Малкова-Халтуриной, и не столь большую его предельную численность, как модель Капицы.

\section{ВЫводы}

Демографический рост обусловлен расширением технологической ниши человечества вследствие развития им жизнесберегающих технологий, мерой которого служит обусловленное ими сокращение коэффициента смертности. Его неотрицательность 
накладывает естественные ограничения на народонаселение, не связанные с какими-либо материальными факторами.

С момента выхода из животного мира развитие вида Hото sapience было неразрывно связано с увеличением его численности. С этой точки зрения все история человечества представляется переходным процессом, который ныне близок к завершению. Мы стоим на пороге кризиса развития даже не цивилизационного, а видового масштаба.

Ключевой нерешенной проблемой теоретической демографии остается построение математической модели демографического перехода. Предложенная в работе феноменологическая модель предполагает постпереходную стабилизацию населения мира. Вместе с тем весьма вероятен переход от экстенсивного развития к интенсивному, сопряженный с элиминацией «лишних» людей. Принципиально важно предвидеть, будет ли она обусловлена лишь падением рождаемости ниже уровня воспроизводства или примет более жесткие формы, связанные с десоциализацией и войнами.

\section{ЛИТЕРАТУРА}

Ичас М. (1994). О природе живого: Механизмы и смысл. М.: Мир. 496 с.

Капица С.П. (1999). Сколько людей жило, живет и будет жить на Земле. Очерк теории роста человечества. М.: Международная программа образования. 240 с.

Капица С.П., С.П. Курдюмов , Г.Г. Малинецкий (1997). Синергетика и прогнозы будущего // Кибернетика: неограниченные возможности и возможные ограничения. М.: Наука. $285 \mathrm{c}$.

Коротаев А.В., А.С. Малков, Д.А. Халтурина (2007). Законы истории: Математическое моделирование развития Мир-Системы. Демография, экономика, культура. Изд. 2 е, испр. и доп. / Отв. ред. Н.Н. Крадин. М.: КомКнига. 224 с.

Cohen J.E. (1995). How many people can the Earth support? New York - London: W.W. Norton \& Company.

Courchamp F., L. Berec, J. Gascoigne (2008). Allee effects in ecology and conservation. New York: Oxford University Press.

Foerster H. von, P.M. Mora , L.W. Amiot (1960). Doomsday: Friday, 13 November, A.D. 2026 // Science. 132(3436): 12911295.

Historical estimates of world population (2006). URL: https://www.census.gov/population/international/data/worldpop/table_history.php (дата обращения: 11.08.2006).

Kremer M. (1993). Population growth and technological change: One million B.C. to 1990 // Q.J. Econ. 108(3): 681716.

Total mid-year population for the world: 19502050 (2016). URL: https://www.census.gov/population/international/data/idb/worldpoptotal.php (дата обращения: 03.02.2016). 


\section{GLOBAL DEMOGRAPHIC THEORY}

\section{ANDREI PODLAZOV}

We develop a mathematical theory of a global demographic process covering the stages both of demographic growth and of the demographic transition.

For most of its history, the population of Homo sapiens has grown explosively. However, in the last few decades growth has slowed down, and world population is tending to stabilize. A quantitative description of our population dynamics, an explanation of its fundamental differences from the population dynamics of other species, and a global demographic forecast are the primary tasks of theoretical demography. To solve them, we introduce the concept of life-saving technologies, the development of which is considered the driving force of history, and formulate the principle of the technological imperative, which directly binds the number of living people to the level of technological development.

Life-saving technologies are created in the course of people's everyday activity, based on earlier developed technologies. On the one hand, their improvement reduces mortality, whose changing coefficient determines the level of technological development, and on the other, it increases the number of people required for the new technologies, thus accelerating demographic growth. However, the lower bound of the mortality coefficient also limits the size of the population, causing a demographic transition, which from the biological point of view is a crisis.

As the technological level approaches its limit, a reorganization of the age structure takes place. Taking formal account of both these factors allows us to construct a phenomenological model of the demographic transition. To determine its parameters, we develop a methodology for processing demographic data pertaining to the stage of growth. The model proposed shows much better agreement with reality than classical models of global demography.

The key effect of the demographic transition model is an increase in the technological niche of mankind, i.e. the ratio of the human population to the level of life-saving technologies. In combination with the growth of the share of adults in the population, this is fraught with developmental instabilities which could lead to global population decline.

Keywords: theoretical demography, global demography, hyperbolic law, blow-up growth, demographic imperative, technological imperative, life-saving technologies, technological niche, demographic transition, limits of growth, age pyramid.

ANdrei V. Podlazov (Tiger@Keldysh.ru), RAS Keldysh Institute of ApPlied Mathematics, Russia.

THE STUDY WAS CARRIED OUT WITH THE SUPPORT OF THE RFBR (PROJECT NO. 15-01-07944-A) AND RFHS (PROJECT NO. 15-03-00404-A).

DATE RECEIVED: MAY 2017.

\section{REFERENCES}

Cohen J.E. (1995). How many people can the Earth support? New York - London: W.W. Norton \& Company.

Courchamp F., L. Berec, J. Gascoigne (2008). Allee effects in ecology and conservation. New York: Oxford University Press.

Foerster H. von, P.M. Mora , L.W. Amiot (1960). Doomsday: Friday, 13 November, A.D. 2026 // Science. 132(3436): 12911295. 
Historical estimates of world population (2006). URL:

https://www.census.gov/population/international/data/worldpop/table_history.php (accessed: 11.08.2006).

Ichas M. (1994). O prirode zhivogo: Mekhanizmy i smysl [On the nature of living: Mechanism and sense]. Moscow: Mir. 496 p.

Kapitza S.P. (1999). Skol'ko lyudey zhilo, zhivet i budet zhit' na Zemle. Ocherk teorii rosta chelovechestva [How many people lived, live and will live on the Earth: An essay on growth of humankind]. Moscow: Mezhdunarodnaya programma obrazovaniya. $240 \mathrm{p}$.

Kapitza S.P., S.P. Kurdyumov, G.G. Malinetskij (1997). Sinergetika i prognozy budushchego [Synergetics and forecast of the future] // Cybernetics: Unlimited possibilities and possible limitations. Moscow: Nauka. 285 p.

Korotaev A.V., A.S. Malkov, D.A. Khalturina (2007). Zakony istorii: Matematicheskoe modelirovanie razvitiya Mir-Sistemy. Demografiya, ekonomika, kul'tura. Izd. 2 e, ispr. i dop. [Laws of history: Mathematical modeling of development of world-system. Demography, economy, culture. 2nd edition] / N.N. Kradin, ed. Moscow: KomKniga. 224 p.

Kremer M. (1993). Population growth and technological change: One million B.C. to 1990 // Q.J. Econ. 108(3): 681716.

Total mid-year population for the world: 1950-2050 (2016). URL:

https://www.census.gov/population/international/data/idb/worldpoptotal.php (accessed: 03.02.2016). 